Int. J. Electrochem. Sci., 11 (2016) 5935 - 5951

International Journal of

ELECTROCHEMICAL

SCIENCE

www.electrochemsci.org

\title{
A Chemometrical Analysis of Voltammetric Data for Simultaneous Determination of Phenobarbital Sodium and Paracetamol Obtained at a Gold Electrode
}

\author{
Milka Avramov Ivić ${ }^{1, *}$, Jelena Antanasijevic ${ }^{2}$, Nemanja Trišović ${ }^{2}$, Davor Antanasijević ${ }^{3}$, Jelena Lović ${ }^{1}$, \\ Dušan Mijin ${ }^{2}$ and Slobodan Petrović ${ }^{2}$ \\ ${ }^{1}$ ICTM - Institute of Electrochemistry, University of Belgrade, Njegoševa 12, Belgrade, Serbia \\ ${ }^{2}$ Faculty of Technology and Metallurgy, University of Belgrade, Karnegijeva 4, 11120 Belgrade, \\ Serbia \\ ${ }^{3}$ Innovation Center of the Faculty of Technology and Metallurgy, Karnegijeva 4, 11120 Belgrade, \\ Serbia \\ "E-mail: milka@tmf.bg.ac.rs
}

doi: $10.20964 / 2016.07 .48$

Received: 24 March 2016 / Accepted: 5 May 2016 / Published: 4 June 2016

The electrochemical behavior of phenobarbital sodium (PBS), paracetamol (PCM) and their binary mixtures was investigated using cyclic voltammetry (CV) and square wave voltammetry (SWV) at a bare gold electrode in a $0.05 \mathrm{M}$ bicarbonate solution. A calibration curve of PBS obtained by SWV had two linear ranges, from 1.0 to $3.0 \mu \mathrm{M}$ and from 5.0 to $35.0 \mu \mathrm{M}$ with a limit of quantification (LOQ) of $0.62 \mu \mathrm{M}$ and a limit of detection (LOD) of $0.19 \mu \mathrm{M}$, while a calibration curve of PCM was determined within the range from 10.0 to $50.0 \mu \mathrm{M}$ with a LOQ of $8.53 \mu \mathrm{M}$ and a LOD of $2.56 \mu \mathrm{M}$. Both drugs underwent oxidation by irreversible, diffusion controlled process. The SW voltammograms of the drug mixtures produced complex, overlapping profiles and a chemometric method was applied for their decomposition. Two different artificial neural network (ANN) architectures, namely back-propagation neural network (BPNN) and general regression neural network (GRNN) were employed for the simultaneous prediction of the concentrations of the drugs in a synthetic sample. The BPNN model had higher accuracy (mean absolute percentage error values were in the range of 3.6-8.4\%) and thus it can be used for the simultaneous determination of PBS and PCM.

Keywords: phenobarbital, paracetamol, voltammetry, chemometrics

\section{$\underline{\text { FULL TEXT }}$}

(C) 2016 The Authors. Published by ESG (www.electrochemsci.org). This article is an open access article distributed under the terms and conditions of the Creative Commons Attribution license (http://creativecommons.org/licenses/by/4.0/). 